\title{
Exploring Student's Acceptance of an EDMODO Learning Management System in Advanced Mobile Applications Course
}

\author{
Nawar Abdulghni Sultan, Mohammed Salim Al-Othman, Hasmek Antranik Warttan

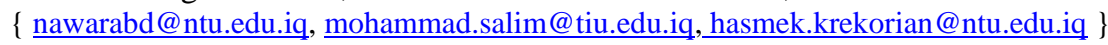 \\ Northern Technical University, Mosul Iraq, Tishk International University, Erbil Iraq, Northern \\ Technical University, Mosul Iraq
}

\begin{abstract}
In the world where social media became its backbone, education should not be an exception. There are various types of online learning management systems which are like social media applications, with certain features tailored for eLearning education. Edmodo is a popular learning management system in the world and the Kurdistan region in Iraq. This study aims to inspect the factors influence using Edmodo learning management system to assist education in a blended classroom, by using an extended Technology Acceptance Model (TAM). This study included a total of 32 students, who attended the course of advanced mobile applications in a blended classroom environment. The results analysis showed that the Edmodo system was impacted very-well and was able to estimate utility and easy to use by the students. Regarding the Motivation factor, it was discovered that there was no significant association with the perception of usefulness. Also, it was found that students were pleased with Edmodo as a Learning Management System and it improved their programming skills through given assignments.
\end{abstract}

Keywords: technology acceptance model, Edmodo, teaching, learning, blended classroom, TAM model, LMS.

\section{Introduction}

Edmodo is a learning management system that delivers its educational services through a website and applying ideas similar to social network apps. It is an improved method to become suitable for the classroom environment by connecting students and teachers in one platform. That lets them exchange notions and participate in educational activities such as discussions, quizzes, and assignments. This system is free and gives the lecture full control overs classes and is a safe atmosphere to control classroom activities, where parents are also permitted to followup their children's performance.

There are many studies that explored using Edmodo in higher education, for example, in the study which focused on higher education in Finland [1], the authors analyzed the impact of using Edmodo as learning support that assists group work through interviews and questionnaires and found that it was helpful to students. Another study was done which focused on investigating views of 12 academics from four universities in Turkey about using Edmodo in education [2], found that it is supportive in education. It was the same results as the other findings [3] [4]. On the other hand, there are other studies concentrated on the impact of using Edmodo in higher 
education level [5] [6] [7], these studies proved that using it can enhance students learning skills significantly and the students have a positive attitude toward using it in their courses.

The motivation for conducting this research is based on authors' observations, the lack of Edmodo's empirical studies as a learning aid method in the teaching of university-level programming courses. This research gap could be tackled by conducting studies on using Edmodo as a secondary aid for improving leadership, communication skills, social skills, problem-solving and teamwork skills of students. One of the vital issues, when we introduce technology, is the level of acceptance and approval of the students to use it [8]. Hence, academics must identify the context that can enlighten and anticipate the benefit of using technology amid students. In the present work, the selection of technology, the trendy model employed is the Technology Acceptance Model (TAM) offered by Davis [9]. The factors or variables involved in this research as shown in Fig. 1 are the typical TAM contains PU, PEoU, $\mathrm{BI}$, approach to use (AtU), and (AU), including the external variables, CQ and Mo.

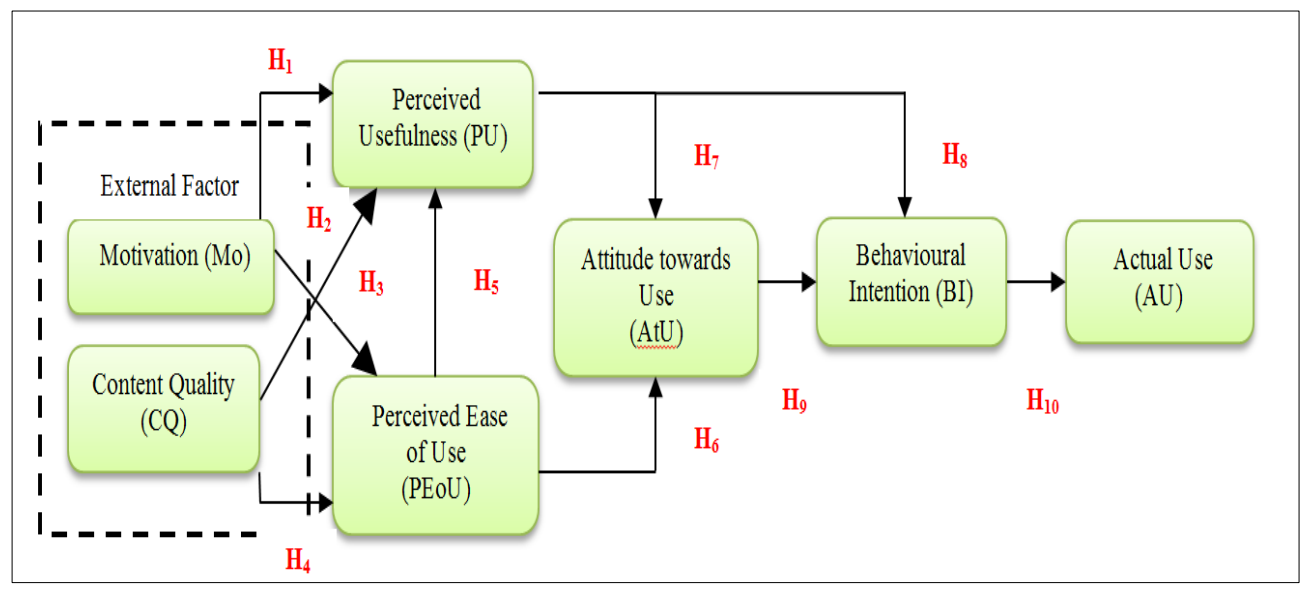

Fig. 1. Organizational Model and Hypotheses [10].

In this paper, the structure proposed and implemented (Figure 1) is adopted by a recent study conducted by Malaysian researchers [10]. Table 1 below summarizes the hypotheses and factors of this study.

Table 1. Proposed factors and hypotheses.

\begin{tabular}{|c|c|c|c|}
\hline Factor & $\begin{array}{l}\text { Associated } \\
\text { Hypotheses }\end{array}$ & First Hypothesis & Second Hypothesis \\
\hline Motivation (Mo) & $\mathrm{H} 1$ and $\mathrm{H} 2$ & $\begin{array}{l}\text { Mo positively influence on } \\
\text { PU }\end{array}$ & $\begin{array}{c}\text { Mo positively } \\
\text { influence on PEoU }\end{array}$ \\
\hline Content Quality (CQ) & $\mathrm{H} 3$ and $\mathrm{H} 4$ & $\begin{array}{c}\text { CQ positively influence on } \\
\text { PU }\end{array}$ & $\begin{array}{c}\text { CQ positively } \\
\text { influence on PEoU }\end{array}$ \\
\hline $\begin{array}{l}\text { Perceived Ease of Use } \\
\text { (PEoU) }\end{array}$ & $\mathrm{H} 5$ and $\mathrm{H} 6$ & $\begin{array}{c}\text { PEoU positively influence on } \\
\text { PU }\end{array}$ & $\begin{array}{l}\text { PEoU positively } \\
\text { influence on AtU }\end{array}$ \\
\hline $\begin{array}{l}\text { Perceived Usefulness } \\
\text { (PU) }\end{array}$ & $\mathrm{H} 7$ and $\mathrm{H} 8$ & $\begin{array}{c}\text { PU positively influence on } \\
\text { AtU }\end{array}$ & $\begin{array}{l}\text { PU positively } \\
\text { influence on } \mathbf{B I}\end{array}$ \\
\hline $\begin{array}{l}\text { Attitude towards Use } \\
\text { (AtU) }\end{array}$ & $\mathrm{H} 9$ & $\begin{array}{l}\text { AtU positively influence on } \\
\text { BI }\end{array}$ & None \\
\hline
\end{tabular}




\begin{tabular}{lccc}
$\begin{array}{l}\text { Behavioural Intention } \\
\text { (BI) }\end{array}$ & H10 & BI positively influence on & None \\
Actual Use (AU) & None & NU & None \\
\hline
\end{tabular}

\section{Motivation (Mo)}

Big motivation is needed for every student to confirm they interact in activities in the Edmodo Content Management System (ECMS) during the semester. Students will be told to do or repeat a more fun activity or having no fun. Hence, the authors assume Mo to have a positive association with the PEoU besides PU. Therefore, hypotheses 1 and 2 are proposed as shown in Table 1.

\section{Content Quality (CQ)}

The authors emphasize that CQ to be offered through hypermedia, videos, texts, and PowerPoint presentations. The CQ is likely to be connected with PU and PEoU. Thus, hypotheses 3 and 4 are suggested as presented in Table 1 .

\section{Perceived Ease of Use (PEoU)}

The present work, uses the PEoU factor to predicts ECMS's student's utilization and the impact of PEoU on PU. Authors assume PEoU will impact PU and students that will remain using ECMS in the coming time. Therefore, the hypotheses 5 and 6 are suggested as shown in Table 1.

\section{Perceived Usefulness (PU)}

This paper selects PU attribute to see how far ECMS usages to students and PU's impact on AtU and Behavioural Intention (BI). Authors supposing PU to affect student AtU and student intent to stay using ECMS in the time ahead. Accordingly, the hypotheses 7 and 8 are offered as stated in Table 1.

\section{Attitude towards Use (AtU)}

This study selected AtU factor is to determine rejection or acceptance of the students towards ECMS. The authors expect AtU to affect student Behavioural Intention (BI) to deploy ECMS. Hence, the hypothesis 9 is stated earlier in Table 1. 


\section{Behavioural Intention (BI)}

In this paper, authors investigate the BI factor of actual use. They assume of using ECMS by the students in the future. Hence, the hypothesis 10 is suggested.

\section{Actual Use (AU)}

In this paper, authors evaluate AU students by the allocated time by students to work with or use ECMS. The present work uses Edmodo by IT department students at Tishk International University while studying advanced mobile application courses for one semester by depending on a structure model called TAM proposed in a recent similar study [10].

Section two will present the methodology of the study, the results presented in section three. Finally, section four is a discussion and conclusion.

\section{METHOD}

This research involved 32 students from the Department of IT, Faculty of Science, Tishk International University participating in the IT 405/A (Advanced Mobile Applications) course. These undergraduates were using Edmodo in this course. After 12 weeks of using Edmodo, an online questionnaire was conducted using Google Forms service. The survey data were acquired by using a self-administered survey containing 31 items gathered under 7 concepts based on the Technology Acceptance Model (TAM) shown in Table 2. The data gathered using Likert Scale $(1=$ strongly disagree, $2=$ disagree, $3=$ average, $4=$ agree, $5=$ strongly agree) for every question extended over five-point. The Cronbach's alpha was found to be 0.912 . This indicator proves that all the factors in the test show high consistency for same perception. For creating content validity, the questions/items and their matching hypotheses were previously dapted according to the current study. The questionnaire adopted by this study could be found online by visiting this link www.shorturl.at/bMSY0. 
Table 2. Cronbach Alpha coefficient values.

\begin{tabular}{||c|c|c|}
\hline \multicolumn{1}{|c|}{ Attributes } & Number of items & Alpha \\
\hline \hline Motivation (Mo) & 5 & .216 \\
\hline Content Quality (CQ) & 8 & .756 \\
\hline Perceived Usefulness (PU) & 5 & .700 \\
\hline $\begin{array}{l}\text { Perceived Ease of Use } \\
\text { (PEpu) }\end{array}$ & 5 & .680 \\
\hline Attitude towards Use (AtU) & 3 & .741 \\
\hline Behavioral Intention (BI) & 4 & .815 \\
\hline Actual Use (Au) & 4 & 1 \\
\hline Total & 31 & .912 \\
\hline
\end{tabular}

\section{RESULTS}

\subsection{Correlated matrix}

Table 2 displays the correlation matrix among the factors considered. The results state that the correlation between all inputs is important $(\mathrm{p}<0.05)$ except the $(\mathrm{MO} \rightarrow$ AtU, BI, AU). The results similarly demonstrate that most of the coefficient of correlation $(r)>0.5$ indicates strong correlation. Conisdering other factors or attributes, it is found that $\mathrm{CQ} \rightarrow \mathrm{AtU}$ presents a high r-value of $0.827(p<0.01)$ whereas the $r$-value of $\mathrm{MO} \rightarrow \mathrm{AU}$ is the lowermost of 0.029 . It also notes that the relation between CQ and (PU, PEoU, AtU, BI, AU) is highly significant ( $\mathrm{p}<0.01$ ).

Table 2. The Correlation Matrix between the TAM Attributes.

\subsection{Multiple Regression}

\begin{tabular}{|c|c|c|c|c|c|c|c|}
\hline Attribute & MO & $\mathrm{CQ}$ & PU & PEoU & Atu & $\mathrm{BI}$ & $\mathrm{Au}$ \\
\hline MO & 1.000 & & & & & & \\
\hline $\mathrm{CQ}$ & $0.407^{\star}$ & 1.000 & & & & & \\
\hline PU & $0.365^{\star}$ & $0.500^{* *}$ & 1.000 & & & & \\
\hline PEoU & $0.533^{* *}$ & $0.661^{* *}$ & $0.749^{* *}$ & 1.000 & & & \\
\hline AtU & 0.301 & $0.827^{* *}$ & $0.562^{* *}$ & $0.815^{* *}$ & 1.000 & & \\
\hline BI & 0.266 & $0.590^{* *}$ & $0.346^{\star}$ & $0.573^{* *}$ & $0.634^{* *}$ & 1.000 & \\
\hline$\underline{A U}$ & 0.029 & $0.651^{* *}$ & $0.432^{*}$ & $0.498^{* *}$ & $0.683^{* *}$ & $0.601^{* *}$ & 1.000 \\
\hline
\end{tabular}

* The correlation was significant at the 0.05 level (2-tailed).

${ }^{\star *}$ The correlation was significant at the 0.01 level (2-tailed). 
Table 3 displays the Multiple Regression Analysis of Matching Person and Technology (MPT) Attributes. The results display the influence of the values of PEoU to PU's related variable (PEoU $\rightarrow \mathrm{PU} ; \beta=0.816$ ). Whereas un-related variables, CQ points are against the related variable PEoU (CQ $\rightarrow$ PEoU; $\beta=0.414)$. Amongst the un-related variables, PEoU and $\mathrm{PU}$ attributes. Then again, the AtU factor is the largest supporter of the BI dependent variable $(\mathrm{AtU} \rightarrow \mathrm{BI} ; \beta=0.851)$.

Table 3. Multiple Regression Analysis of MPT.

\begin{tabular}{|c|c|c|c|c|c|c|}
\hline DV & IV & $\mathrm{R}^{2}$ & $\operatorname{Beta}(\beta)$ & Standard error of $\beta$ & t-statistics & significance \\
\hline \multirow[t]{3}{*}{ PU } & Mo & \multirow[t]{3}{*}{0.562} & -0.068 & 0.203 & -0.334 & $P>0.05$ \\
\hline & $\mathrm{CQ}$ & & 0.013 & 0.164 & 0.080 & $P>0.05$ \\
\hline & PEoU & & 0.816 & 0.189 & 4.314 & $P<0.01$ \\
\hline \multirow[t]{2}{*}{ PEoU } & Mo & \multirow[t]{2}{*}{0.521} & 0.414 & 0.181 & 2.286 & $P<0.05$ \\
\hline & $\mathrm{CQ}$ & & 0.500 & 0.130 & 3.852 & $P<0.01$ \\
\hline \multirow[t]{2}{*}{ AtU } & $\mathrm{PU}$ & \multirow[t]{2}{*}{0.669} & -0.111 & 0.164 & -0.681 & $P>0.05$ \\
\hline & PEoU & & 0.985 & 0.174 & 5.652 & $P<0.01$ \\
\hline \multirow[t]{2}{*}{$\mathrm{BI}$} & $\mathrm{PU}$ & \multirow[t]{2}{*}{0.402} & -0.022 & 0.233 & -0.094 & $P>0.05$ \\
\hline & AtU & & 0.851 & 0.226 & 3.768 & $P<0.01$ \\
\hline $\mathrm{Au}$ & $\mathrm{BI}$ & 0.362 & 0.885 & 0.211 & 4.192 & $P<0.01$ \\
\hline
\end{tabular}

The outcomes of the hypotheses model is presented in Figure 2. Regarding PU, the results reveal the properties of CQ (H3: CQ $\rightarrow$ PU; $\beta=0.13, p>0.05)$ and PEoU properties (H5: PEoU $\rightarrow$ $\mathrm{PU} ; \beta=0.816, \mathrm{p}<0.01)(\mathrm{H} 1: \mathrm{Mo} \rightarrow \mathrm{PU} ; \beta=-0.068, \mathrm{p}<0.05)$ did not significantly influenced the PU. The three factors state a $69.3 \%$ variance in PU. The Mo properties (H2: Mo $\rightarrow$ PEoU; $\beta=0.414, \mathrm{p}<0.05)$ and CQ attributes (H4: CQ $\rightarrow$ PEoU; $\beta=0.500, p<0.01)$ in PEoU. In the meantime, the PEoU properties (H6: PEoU $\rightarrow$ AtU; $\beta=0.985, p<0.01$ ) expressively affected AtU in a positive way but in a different way with PU. The AtU results reveal $76.6 \%$ of variance. In addition, $\mathrm{PU}(\mathrm{H} 8 \mathrm{PU} \rightarrow \mathrm{BI} ; \beta=-0.022, \mathrm{p}>0.05$ ) shown significant negative association with BI while AtU properties (H9: AtU $\rightarrow \mathrm{BI} ; \beta=0.851, \mathrm{p}<0.01$ ). These two properties state $52.7 \%$ of the variances in BI. Whereas the $\mathrm{BI}$ feature $(\mathrm{H} 10: \mathrm{BI} \rightarrow \mathrm{AU} ; \beta=0.885, \mathrm{p}<0.01)$ expressively influenced PS with $32.6 \%$ variance in AU.

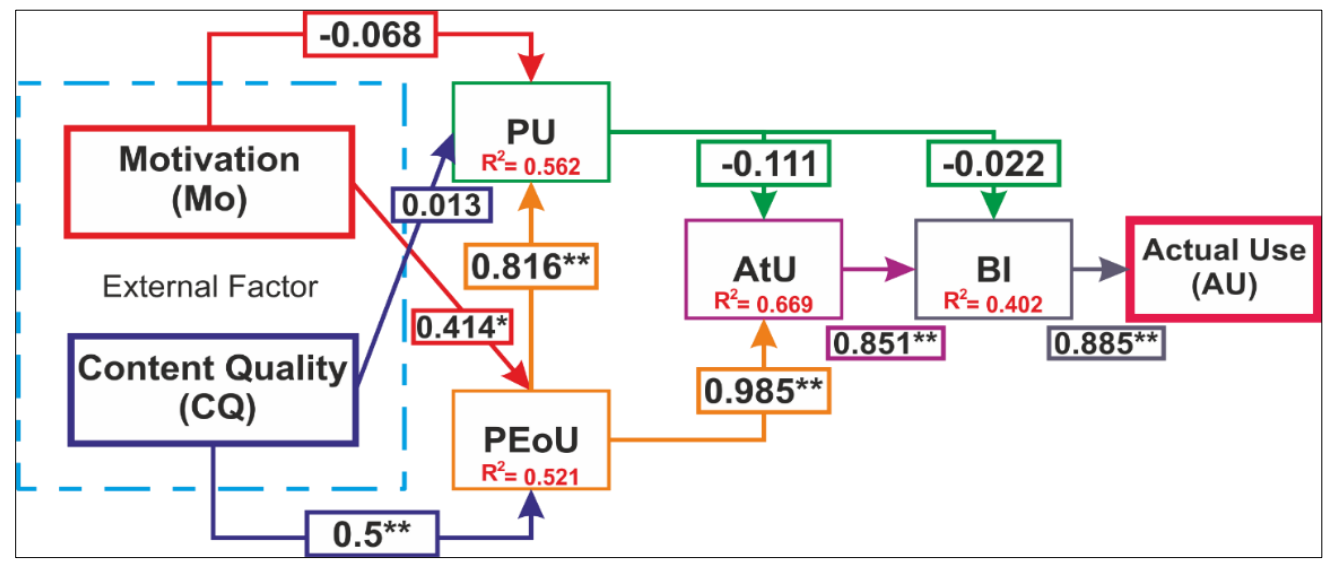


Fig. 2. Testing the Hypotheses of the Structural Model

Table 4 The charateristics of the TAM.

Table 4. Outcomes of Hypotheses

\begin{tabular}{|l|l|l|l|l|}
\hline Hypothesis & Effects & Direction & Path Coefficient & $\begin{array}{l}\text { Result (Support } \\
\text { to Hypotheses) }\end{array}$ \\
\hline $\mathrm{H} 1$ & Mo $\rightarrow$ PU & Negative & -0.068 & Not Supported \\
\hline $\mathrm{H} 2$ & Mo $\rightarrow$ PEoU & Positive & 0.414 & Supported \\
\hline $\mathrm{H} 3$ & $\mathrm{CQ} \rightarrow \mathrm{PU}$ & Negative & 0.013 & Not Supported \\
\hline $\mathrm{H} 4$ & $\mathrm{CQ} \rightarrow \mathrm{PEoU}$ & Positive & 0.500 & Supported \\
\hline $\mathrm{H} 5$ & PEoU $\rightarrow$ PU & Positive & 0.816 & Supported \\
\hline $\mathrm{H} 6$ & PEoU $\rightarrow$ AtU & Positive & 0.985 & Supported \\
\hline $\mathrm{H} 7$ & PU $\rightarrow$ AtU & Negative & -0.111 & Not Supported \\
\hline $\mathrm{H} 8$ & $\mathrm{PU} \rightarrow \mathrm{BI}$ & Negative & -0.022 & Not Supported \\
\hline $\mathrm{H} 9$ & $\mathrm{AtU} \rightarrow \mathrm{BI}$ & Positive & 0.851 & Supported \\
\hline $\mathrm{H} 10$ & $\mathrm{BI} \rightarrow \mathrm{AU}$ & Positive & 0.885 & Supported \\
\hline
\end{tabular}

\section{CONCLUSION AND DISCUSSION}

External variable acts as a central part in influencing PEoU toward Edmodo. This result is confirmed partially by a study conducted by [11] that Mo has influence on the PEoU and PU. As stated by [11], the role of a system that denotes to motivation impacts the PU and PEoU in a positive way. However, in our results, motivation factor didn't affect perceived usefulness PU which mean that students don't have confidence in using an ECMS system would enhance their learning performance because of lack of motivation such as fun activities or other unknown reasons that need more investigation in future research.

The results of this paper don't confirm the hypothesis 3 but endorse hypothesis 4 . In addition, using text, video, and audio allow students to understand the learning materials even if influencing Edmodo usability. When there is simple access to the contents with the influence the PEoU using effective technology [11]. [12] stated that high CQ affected impressions of feasibility and impressions of assessment. Nevertheless, there are various findings. [13] stated that CQ does not expressively influence PEoU but remarkably affected the assessment perception. As most students are acquainted with technology appliances, the tools and usability of the technology are not a barrier for them.

Regarding perceived usefulness, the results approve those of other studies [14] stating that the PU factor to be among the toughest of the factors from the technology acceptance model. Therefore, students who believe the LMS or any other system is beneficial in their learning are more probably to adopt it. There is one important remark in using behavioral intention. This 
result is not matching the one found in [15]. A research conducted by [15] stated that AtU was not an attribute that could influence on BI. In [16] stated that users are expected to have a significant AtU if they applied technology to enhance their productivity and performance. Another study done by [17] concluded that AtU was not suitable for AU or BI. His study shows that $\mathrm{AU}$ and $\mathrm{BI}$ influence PEoU and PU but have no influence into AtU through BI.

This work recommends Hypothesis 9 since those fourth-year students have previous experience with ECMS in other previous courses of the last three years. Student AtU might provide experience and knowledge applying ECMS. Finally, this paper confirms Hypothesis 10 since students were using ECMS previously, and there is no alternative for them to use for interacting with their lecturers in getting lecture notes, submitting assignments, and receiving notifications about any upcoming duty such as quizzers and exams. This finding seeks to raise their confidence while changing the AtU towards ECMS.

Regarding results from other studies that focused on different LMSs rather than Edmodo, there is research conducted by Binyamin [18] studied the acceptance level of Blackboard LMS, however, the present results show the students quite affected byy the CQ.

Another research was done by Yeou[7] intended to create a new methodology; however, the research findings are different from the present work because they show that PU and PEOU are substantial factors of students' to use WBLE. Anyhow, student demographics have no influence on PEOU and PU.

Last study was done by Amir Shah[19] which explores the impact of TAM's two basic Perceived factors concerning the Usefulness and Ease of Use in addition to some extra factors (system quality, facilitation conditions, self-efficacy, and faculty support). The collected data was from various universities of twin cities (Islamabad \& Rawalpindi) where LMS/e-learning is being used obligatory. As the objective is to get information from the students who are quite used to with the LMS, the universities were purposefully selected where the mode of education is online/distance education. A total of 315 questionnaires were considered, out of this, 237 valid responses were used for analysis. It shows there is a important impact of all these factors on student's attitudes towards the use of Moodle LMS. However, our study results found that PU doesn't influence many factors such as Mo, CQ, AtU, BI which might indicate that most students believe there is a lack of motivation and content quality that drives them towards using Edmodo LMS.

At last, future research may try to determine the acceptance and usage of LMSs among students and to identify impact factors.

\section{References}

[1] V. Paliktzoglou and J. Suhonen, "Microblogging in Higher Education", Journal of Cases on Information Technology, vol. 16, no. 2, pp. 39-57, 2014. Available: 10.4018/jcit.2014040104.

[2] G. Durak, "Using Social Learning Networks (SLNs) in Higher Education: Edmodo Through the Lenses of Academics", The International Review of Research in Open and Distributed Learning, vol. 18, no. 1, 2017. Available: 10.19173/irrodl.v18i1.2623.

[3] J. Ngo and A. Ngadiman, "The Impacts of Edmodo on Students' Performance in ESP Classrooms", KnE Social Sciences, vol. 3, no. 10, p. 369, 2019. Available: 10.18502/kss.v3i10.3918. [4] Alqahtani, "The Use of Edmodo: Its Impact on Learning and Students' Attitudes Toward It", Journal of Information Technology Education: Research, vol. 18, pp. 319-330, 2019. Available: 10.28945/4389. 
[5] D. Nurhayati, "Students' Perspective on Innovative Teaching Model Using Edmodo in Teaching English Phonology: A Virtual Class Development", Dinamika Ilmu, vol. 19, no. 1, pp. 13-35, 2019. Available: 10.21093/di.v19i1.1379.

[6]M. Salim, Educational Technology Implementation in Private Universities in Erbil City", International Journal of Social Sciences \& Educational Studies, vol. 5, no. 3, 2019. Available: 10.23918/ijsses.v5i3p303.

[7] M. Yeou, "An Investigation of Students' Acceptance of Moodle in a Blended Learning Setting Using Technology Acceptance Model", Journal of Educational Technology Systems, vol. 44, no. 3, pp. 300318, 2016. Available: 10.1177/0047239515618464.

[8] F. Davis and V. Venkatesh, "Toward Preprototype User Acceptance Testing of New Information Systems: Implications for Software Project Management", IEEE Transactions on Engineering Management, vol. 51, no. 1, pp. 31-46, 2004. Available: 10.1109/tem.2003.822468.

[9] F. Zain, E. Hanafi, Y. Don, M. Yaakob and S. Sailin, "Investigating Student's Acceptance of an EDMODO Content Management System", International Journal of Instruction, vol. 12, no. 4, pp. 1-16, 2019. Available: 10.29333/iji.2019.1241a.

[10] J. Wu, R. Tennyson and T. Hsia, "A study of student satisfaction in a blended e-learning system environment", Computers \& Education, vol. 55, no. 1, pp. 155-164, 2010. Available: 10.1016/j.compedu.2009.12.012.

[11] K. Pituch and Y. Lee, "The influence of system characteristics on e-learning use", Computers \& Education, vol. 47, no. 2, pp. 222-244, 2006. Available: 10.1016/j.compedu.2004.10.007.

[12] D. Zhang, J.K. Nunamaker, Powering E-learning in the new millennium: an overview of e-learning and enabling technology, Information Systems Frontiers 5 (2) (2003) 207 - 218.

[13] J. Wu, R. Tennyson, T. Hsia and Y. Liao, "Analysis of E-learning innovation and core capability using a hypercube model", Computers in Human Behavior, vol. 24, no. 5, pp. 1851-1866, 2008. Available: 10.1016/j.chb.2008.02.008.

[14] H. Min Khor, M. Pin Tan, P. Jun-Hua Poi and N. Saedon, "Pressure ulcers associated mortality among older patients in a large teaching hospital in Malaysia", Australasian Journal on Ageing, vol. 33, pp. 65-65, 2014.

[15] P. Sun and J. Scott, "Exploring the divide - organizational learning and learning organization", The Learning Organization, vol. 10, no. 4, pp. 202-215, 2003. Available: 10.1108/09696470310476972.

[16] P. Chau and P. Hu, "Information Technology Acceptance by Individual Professionals: A Model Comparison Approach", Decision Sciences, vol. 32, no. 4, pp. 699-719, 2001. Available: 10.1111/j.1540-5915.2001.tb00978.x.

[17] V. Venkatesh and F. Davis, "A Theoretical Extension of the Technology Acceptance Model: Four Longitudinal Field Studies", Management Science, vol. 46, no. 2, pp. 186-204, 2000. Available: 10.1287/mnsc.46.2.186.11926.

[18] S. Binyamin, M. Rutter and S. Smith, "Extending the Technology Acceptance Model to Understand Students' Use of Learning Management Systems in Saudi Higher Education", International Journal of Emerging Technologies in Learning (iJET), vol. 14, no. 03, p. 4, 2019. Available: 10.3991/ijet.v14i03.9732.

[19] S. A. Shah, I. U. K. Marwat, A. U. Din, and A. Khan, "Impact of various factors on student's attitude towards adoption of Learning Management System (LMS) in Pakistan," 2017. 